\title{
Strategies to Streamline the U.S. Army's Acquisition Approval Process
}

\author{
Donald E. Schlomer \\ LVCG\&E Incorporated, Orlando, Florida \\ Douglas G. Campbell \\ Walden University
}

\begin{abstract}
This qualitative single-case study explored strategies that senior U.S. Army Commanders could use to reduce the approval time for an acquisition category (ACAT) III need document in the Joint Capabilities Integrated Development System (JCIDS). Data came from historical documents and semistructured interviews of 30 ACAT III requirement writers and senior U.S. Army commanders with expertise in JCIDS. The conceptual framework was Goldratt's theory of constraints. Miles, Huberman, and Saldana's data analysis method was used to identify themes. Six themes emerged that yielded six possible strategies to reduce approval time: (a) define and implement an objective goal, (b) simplify the process and decrease redundancy by reducing or eliminating irrelevant levels of review, (c) determine the optimum number of reviews necessary for the desired outcome, (d) determine if the chief of staff of the Army should be the approving authority for an ACAT III need document, (e) determine the appropriate offices and individuals that should be consulted about the need document during the world wide review process, and (f) enhance training for JCIDS personnel participating in the need approval process. These findings are already contributing to positive organizational and social change because they have already been adopted by the U.S. Army as the basis for a significant effort to streamline the acquisition process, save U.S. taxpayer funding, and enhance the combat efficiency of the U.S. Army, thereby increasing the safety and security of the United States and its citizens.
\end{abstract}

Keywords: acquisition, Army, JCIDS, ACAT III

\section{Introduction}

In 2014, the members of the U.S. Senate and House of Representatives Armed Services Committees jointly wrote a letter to the president and CEO of the National Defense Industrial Association, asking for suggestions on how to improve the Department of Defense (DOD) acquisition system (U.S. House of Representatives, Armed Services Committee, 2014). In 2015, a U.S. Government Accountability Office (GAO) report again identified the length of time of the acquisition need approval process and the inability to produce products using current technology as major constraints on military project management efficiency (GAO, 2015).

Department of Defense personnel develop the military's equipment needs and use the U.S. government acquisition system to make purchases (GAO, 2013). The Joint Capabilities Integrated Development System (JCIDS) timeline for approval of a need requirement is excessively long at 337 days (Chairman of the Joint Chiefs of Staff, 2015b; GAO, 2012). The GAO report suggested that a review be conducted of the JCIDS process. In November 2015, Congressional leaders approved the National Defense Authorization Act. Section 810 of the Act requires the Secretary of Defense and the 
chair of the joint chiefs of staff to review the JCIDS approval process to establish a streamlined process to develop needs for acquisition programs (National Defense Authorization Act, 2016).

DOD and U.S. Military acronyms, including some used in Figures 1 and 2, are explained in the Appendix. Both Figures 1 and 2 graphically portray some of the complexity of the JCIDS process. Figure 1 represents a macroview of the overall JCIDS process, and Figure 2 addresses only the initial JCIDS document approval steps monitored through the Army Capabilities Integration Center (ARCIC). While figures 1 and 2 do not comprehensively portray the entire ACAT III need to approval process, these figures do adequately communicate the challenging complexity of the entire process.

\section{Method}

\section{Purpose, Population, Data Collection, and Analysis}

The purpose of this qualitative, descriptive single-case study was to explore strategies that senior U.S. Army commanders might use to reduce the JCIDS approval time for a specific military need acquisition category (ACAT). That category is ACAT III, which includes the most common individual service member's military equipment. This category does not include high-cost major weapons systems (Gass, 2012). The primary research question was this: What are strategies senior U.S. Army commanders might use to reduce the JCIDS approval time for an ACAT III military need? There were two secondary research questions:

Research Question 1: What are the functions within the JCIDS process that may be a constraint by adding time to the ACAT III approval process?

Research Question 2: What are the strategies that may be used to address possible constraints by reducing the time of the ACAT III approval process?

Data for this study came from U.S. Army historical documents and semistructured interviews of 30 ACAT III requirement writers and senior U.S. Army commanders having expertise in JCIDS located at Fort Benning, Georgia; Fort Eustis, Virginia; and MacDill Air Force Base, Florida. An interview protocol guide was used to reduce bias and promote data reliability. Member checking technique was employed to increase the reliability of the data from the interviews.

Miles, Huberman, and Saldana's (2014) data analysis method was used to identify themes and possible strategies. This method includes transcribing interviews, collecting field notes, coding with keywords, counting frequencies of words, displaying data in an organized manner, data source triangulation to enhance data validity, and linking relevant data to form themes. Specialized computer research software was employed to assist with the analysis of data from the interviews and field notes and to identify key themes. Those key themes and information found in the literature review were correlated and then viewed through the lens of the theory of constraints (TOC) to discover potential strategies. 


\section{Complete JCIDS Process}



Figure 1. Definition of all the staffing required for acquisition category (ACAT) documents. Process ending in $A$ is providing an ACAT document to Army Capabilities Integration Center (ARCIC) for review. Process A-B shows ARCIC's approval process. Process B-C shows ARCIC staffing through Headquarters (HQ) Department of the Army (DA). Process $C-D$ shows ARCIC staffing through the Army Requirements Oversight Council (AROC). Process D-G shows ARCIC staffing through Joint Requirements Oversight Council (JROC; ARCIC, 2016). JCIDS = Joint Capabilities Integrated Development System; TRADOC = Training and Doctrine Command; $C D D=$ capabilities development document; Div = division; $A W G=$ Army Working Group; $A R B=$ Army Review Board; $A C B=$ Army Control Board; JSD = joint staffing designator; $F C B=$ functional capabilities board; $J C B=$ Joint Control Board; JROCM = Joint Review Operations Committee Management. By U.S. Department of the Army, Army Capabilities Integration Center, Complete JCIDS Process, 2016. No copyright. 


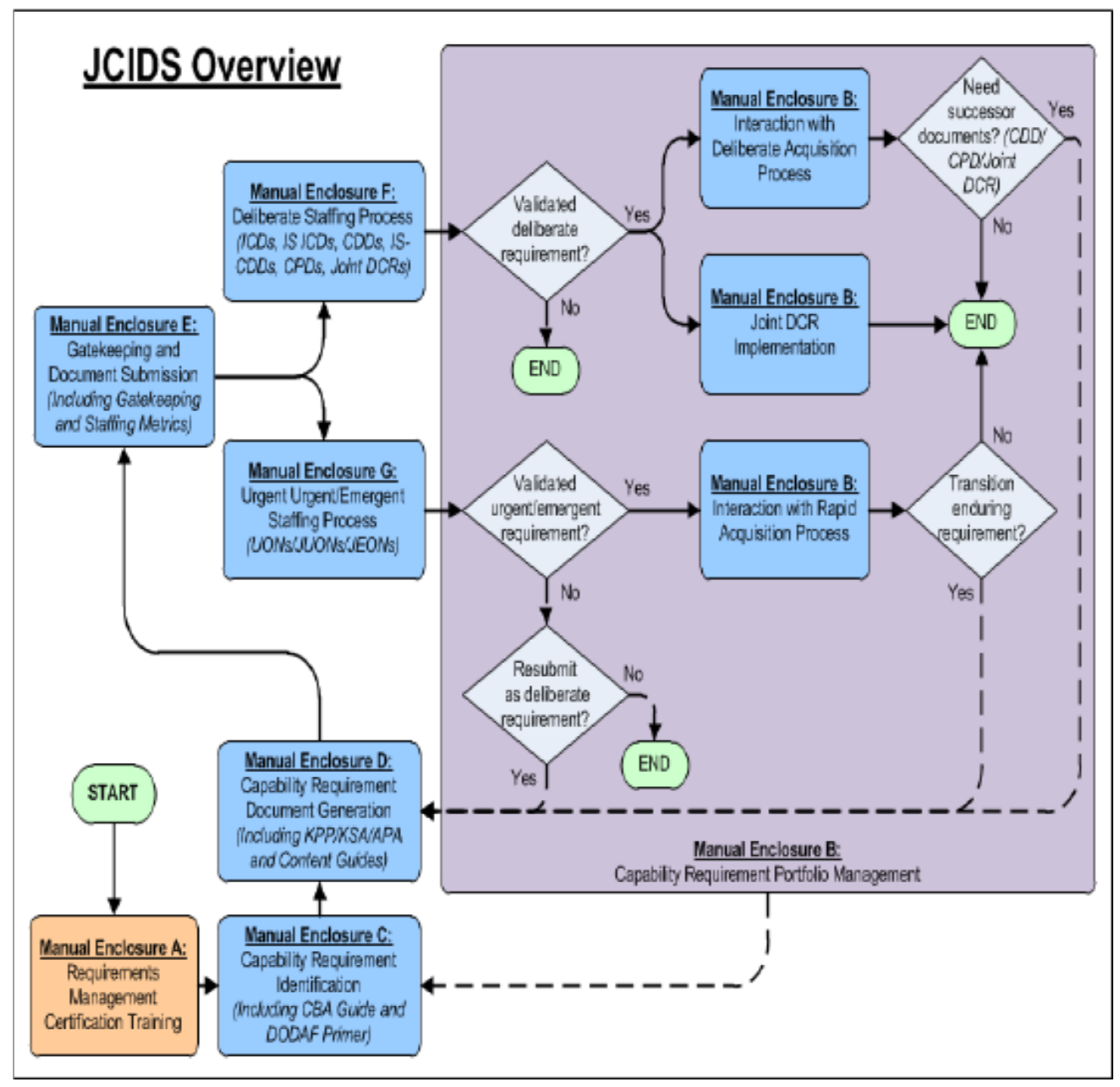

Figure 2. Defining the initial Joint Capabilities Integrated Development System (JCIDS) document approval steps monitored through Army Capabilities Integration Center (ARCIC). Process starts with Manual Enclosure A. Manual Enclosures $B$ and $C$ are the decision activities conducted at the Centers of Excellence as to which document and process to use. Manual Enclosure D activities conducted at the Centers of Excellence with the output sent to Manual Enclosure E, ARCIC gatekeeper. The process ends with Manual Enclosures F or $G$ activities conducted by the ARCIC gatekeeper. ICD = initial capabilities document; JS JCS = Joint Chief of Staff; $C D D=$ capabilities development document; JS-CDD = Joint Staff CDD; CPD = capabilities production document; $D C R=$ defense change recommendation; UON = Urgent Operational Need; JUON = Joint Urgent Operational Need; JEON = Joint Emergent Operational Need; $K P P=$ key performance parameter; $K S A=k e y$ system attributes; $A P A=$ additional performance attribute; $C B A=$ capability-based assessment; DODAF = Department of Defense architecture framework. Identified from the U.S. Chairman of the Joint Chiefs of Staff, Chairman of the Joint Chiefs of Staff Instruction, 3170.01I, 2015, p. A2. No copyright. 


\section{Limitations}

The scope of this study was restricted exploring strategies associated with only one category, ACAT III, within the JCIDS approval process. Data was collected from only 30 of the approximately 1,000 requirement writers and senior U.S. Army commanders. The research locations were limited to Ft. Benning, Ft. Eustis, and MacDill. Exploring strategies through the paradigm of TOC assists in identifying process constraints but may obscure other issues and potential solutions.

\section{Conceptual Framework}

The conceptual framework was Goldratt's TOC (Goldratt \& Cox, 1984). TOC has, as a core concept that any process or system that fails to achieve maximum efficiency or effectiveness due to inherent constraints (Goldratt \& Cox, 2014). A system constraint limits process throughput (Goldratt, 1990). Identification and exploration of those constraints may provide a strategy that can streamline and generate faster throughput in the process (Goldratt \& Cox, 2014). In this study, Miles et al.'s (2014) data analysis method was used to identify themes and possible strategies.

\section{Synthesis of the Literature Review}

Worger, Jalao, Wirthlin, Colombi, and Wu (2014) found that JCIDS is actually a process as opposed to a system within the DOD acquisition system. The DOD acquisition system is a complex system of systems that includes but is not limited to the Defense Acquisition System, Joint Operation Planning and Execution System, Planning Programming Budgeting and Execution System, and JCIDS (Chairman of the Joint Chiefs of Staff, 2015a). This complex and difficult-to-understand web of systems evolved over decades, and the complexity of the entire system can partially be attributed to Congressional involvement and Congressional mandates. Numerous attempts to improve the system have been only marginally successful. With the exception of this study, there are no relevant peerreviewed publications that address the activities and functions of the JCIDS approval process. However, peer-reviewed publications exist on a somewhat similar Federal Drug Administration approval process, but these publications were of limited assistance due to significant differences in the bureaucracies. There are peer-reviewed publications concerning the overall DOD acquisition and contracting process.

For years, reports written by different individuals within the GAO stated the many issues affecting the ability of government personnel within the Defense Acquisition System to acquire and deliver current technology and equipment to the warfighter. With the current state of world uncertainty, the ability of our military to protect the citizens of the United States has never been more important. The warfighters' ability to perform their duties successfully are directly associated with the capability and effectiveness of the equipment they use. Currently, technology evolves approximately every 14 to 18 months (GAO, 2016). The current time period to develop and approve a need through the JCIDS process is 337 days (Chairman of the Joint Chiefs of Staff, 2015b; GAO, 2012). Thus, the U.S. Congress approved the National Defense Authorization Act in Fiscal Year 2016 to mandate the Secretary of Defense to streamline the acquisition process.

Several system improvement process applications such as Total Quality Management, Business Process Improvement, Six Sigma, and TOC might support the development of strategies for senior Army commanders. All of these applications have as a core purpose the ability to identify and possibly improve throughput in a process. However, only one application, TOC, has the ability to 
improve a process without the use of statistical analysis (Goldratt \& Cox, 2014). The JCIDS is not a manufacturing process, so accumulating statistical data for analysis is difficult. Therefore, applying the TOC to generate possible strategies for senior Army commanders to address the JCIDS process is the operative approach.

\section{Findings}

\section{Key Facts Identified}

Based on the analysis of current and historical organizational documents, JCIDS personnel approved zero needs in fewer than 250 days and one in 894 days. The median approval time was 506 days. Additionally, the average time to fund, contract, and deliver an ACAT III need was 420 days. However, as Schwartz (2014) suggested, technology changes every 14-18 months, or 420-540 days. Consequently, a delivered ACAT III solution may not incorporate current technology.

\section{Six Emergent Themes}

Six themes were identified from interview data and organizational documents. These themes indicated six areas of system constraints: (a) the levels of approval, (b) the number of reviews, (c) whether the chief of staff of the Army should approve an ACAT III need, (d) the value of worldwide staffing, (e) the education and experience of JCIDS personnel, and (f) absence of an objective goal to reduce the time of the JCIDS process. Further analysis resulted in the identification of six potential strategies for senior U.S. Army Commanders to address those system constraints that may reduce the approval time of an ACAT III need document in the JCIDS approval process.

\section{Strategy 1: Define and implement an objective goal to reduce the approval time}

Goldratt and Cox (2014) stated that the goal is the key to defining and measuring the throughput of a process. Army leadership may consider the objective goal to include measurable decrements of time anticipated of the improvement efforts for the JCIDS approval process for an ACAT III document. The goal may include the anticipated amount of time to implement the efforts to obtain the measurable decrements of time in the JCIDS approval process.

\section{Strategy 2: Simplify and decrease redundancy by reducing or eliminating levels of review}

This strategy would include the determination of the appropriate level of approval for an ACAT III need document in the JCIDS approval process. Analysis of the research data supports that multiple levels of approval negatively impacts the approval time of an ACAT III need document in the JCIDS approval process. Senior U.S. Army commanders might consider that an ACAT III need document should not have the same approval level as an ACAT II or I document.

\section{Strategy 3: Determine the optimum number of reviews}

This strategy may address the reasoning behind having personnel in an Army Requirements Resource Board, Army Working Group, Army Control Board, Joint Review Board, Joint Working Group, and a Joint Control Board approve an ACAT III need document prior to chief of staff of the Army final approval. Army leadership may consider eliminating required approvals that are redundant, or provide limited value. Army leadership may consider combining groups that can approve an ACAT III need document for both the Army and for joint services efforts. 


\section{Strategy 4: Determine if the chief of staff of the Army should be the approving authority}

Army leadership may consider an alternative person, office, or commander. Thus, the appropriate person to approve an ACAT III need document in the JCIDS approval process should be determined. The analysis of the data supports a lower level of approval of an ACAT III need document. Although, the participants could not agree on who should approve an ACAT III need document.

\section{Strategy 5: Determine the value of the worldwide staffing process}

Army leadership might consider allowing the creation of a key stakeholder group that could assist in writing an ACAT III need document instead of employing worldwide staffing of the document. Alternately, leaders could identify the appropriate number of organizations and leaders that should be included in the worldwide staffing process. If key stakeholders assist in writing an ACAT III need document and represent the majority of the units included in worldwide staffing, this arrangement should reduce the processing and approval time.

\section{Strategy 6: Enhance the training of JCIDS personnel}

Training could be developed to ensure that all current and future personnel, such as document writers, have the necessary skills, training, and general preparation to contribute to an efficient approval process. Army leadership might consider course description, training on writing an ACAT III document, method and length of training, location of the training, the number of training sessions offered, and a method for continuous training. Army leadership also might consider training ACAT III document approvers assigned to the JCIDS approval process.

\section{Discussion}

\section{Significance and Potential Impact of This Study}

U.S. senior military leadership have increasing concerns that U.S. warfighters do not have equipment with most current technology because of the length of time for an ACAT III need approval. This situation puts U.S. warfighters at increased risk and increases society's risk of attack. When implemented, the strategies provided by in this research may result in enhanced U.S. warfighters' battlefield efficiency and potentially contribute to national security, therefore improved safety for U.S. citizens. Additionally, the exploration of the suggested strategies may allow senior U.S. Army commanders to promote a learning environment for the JCIDS personnel, document writers, with training in document writing and critical thinking. This is the first purely academic published research on this subject, and the significance of the study has already been acknowledged by some of the highest responsible individuals in the DOD. The findings of this research have already become the framework for a significant effort by the chief of staff of the U.S. Army to streamline the need approval process within the acquisition system. Additionally, this research could inform other governmental agencies efforts to streamline their acquisition systems.

\section{Potential for Positive Social Change}

Positive social change may occur because the reduced time for a need approval may also generate a cost savings for the U.S. taxpayer. The timely delivery of upgraded equipment to the U.S. warfighters could also safe lives, both military and civilian. Additionally, U.S. citizens may also benefit from an increase in the number of jobs available when private corporations have increased funds because of reduced investments in outdated technology. 


\section{Recommendations for Further Research}

This study is the first of its kind to research the JCIDS approval process. There are other portions of JCIDS process and other acquisition categories that would benefit from a similar research approach. To assist in the planning for implementing of each of the recommended strategies a similar research approach could be used to identify possible viable implementation options. The DOD is not the only part of the U.S. government that purchases large amounts of unique mission specific equipment and supplies. Other governmental agencies could also benefit from a similar research approach. A quantitative longitudinal study could be designed to assess the effectiveness of any of the implemented strategies, perhaps with a qualitative component to explore further any process constraints that are not being effectively mitigated. However, that may first require a quantitative analysis of the ACAT III approval process to determine a more detailed quantitative baseline for comparison. The TOC, while originally oriented to manufacturing, has through this research been shown to be viable conceptual framework to explore potential constraints in nonmanufacturing processes. Therefore, the TOC could be used as the lens of analysis through which to explore systematic approaches to governmental and nongovernmental organizational planning, logistics and operations.

\section{Conclusion}

The findings of this research confirmed that the JCIDS process does have multiple system constraints that significantly slow the approval and eventual acquisition of up-to-date warfighter equipment. The constraints as identified by the emergent themes are potentially addressable through the strategies recommended in this study. By developing and implementing any of these six recommended strategies, senior U.S. Army commanders may reduce the approval time of an ACAT III need document. That, in turn, could generate a possible cost savings for U.S. taxpayers. Therefore, the resulting increased efficiency might benefit future generations of U.S. government personnel, U.S. warfighters, and U.S. citizens. These findings are already contributing to positive organizational and social change because they have already been adopted by the U.S. Army as the basis for a significant effort to streamline the acquisition process and save U.S. taxpayer funding and enhance the combat efficiency of the U.S. Army, thereby increasing the safety and security of the United States and its citizens.

\section{References}

Chairman of the Joint Chiefs of Staff. (2015a). Joint capabilities integration and development system (JCIDS) instruction. Retrieved from https://dap.dau.mil/policy/Documents/2015/CJCSI_3170_01I.pdf

Chairman of the Joint Chiefs of Staff. (2015b). Manual for the operations of the joint capabilities integration and development system. Retrieved from https://dap.dau.mil/policy/Documents/2015/JCIDS_Manual_with_errata_through_20151218.p $\mathrm{df}$

Gass, S. M. (2012). Second language acquisition: An introductory course. New York, NY: Routledge.

Goldratt, E. M. (1990). What is this thing called theory of constraints and how should it be implemented? Great Barrington, MA: North River Press. 
Goldratt, E. M., \& Cox, J. (1984). The goal: A process of ongoing improvement. Great Barrington, MA: North River Press.

Goldratt, E. M., \& Cox, J. (2014). The goal: A process of ongoing improvement (4th ed.). Great Barrington, MA: North River Press.

Miles, M. B., Huberman, A. M., \& Saldana, J. (2014). Qualitative data analysis: Method source book. Sage, Los Angeles.

National Defense Authorization Act of 2016, 114, U.S.C. 1356 (2016). Retrieved from https://www.congress.gov/bill/114th-congress/senate-bill/1356/text

Schwartz, M. (2014). Congressional Research Service. (2014). Defense acquisitions: How DOD acquires weapon systems and recent efforts to reform the process. Retrieved from https://www.fas.org/sgp/crs/natsec/RL34026.pdf

U.S. Government Accountability Office (GAO). (2012). Defense management: Guidance and progress measures are needed to realize benefits from changes in DOD's joint requirements process. Retrieved from http://www.gao.gov/products/GAO-12-339

U.S. Government Accountability Office (GAO). (2013). Defense acquisitions: Assessments of selected weapons programs. Retrieved from http://www.gao.gov/products/GAO-13-294sp

U.S. Government Accountability Office (GAO). (2015). Defense acquisitions: Assessments of selected weapons programs. Retrieved from http://www.gao.gov/products/GAO-15-342sp

U.S. Government Accountability Office (GAO). (2016). Defense acquisitions: Assessments of selected weapons programs. Retrieved from http://www.gao.gov/products/GAO-16-329sp

U.S. House of Representatives, Armed Services Committee. (2014, April 2). Bipartisan national security leaders reach out to stakeholders on DOD reform [Press release]. Retrieved from https://armedservices.house.gov/news/press-releases/bipartisan-national-security-leadersreach-out-stakeholders-dod-reform

Worger, D., Jalao, E. R., Wirthlin, J. R., Colombi, J., \& Wu, T. (2014).Intervention strategies for the department of defense acquisition process. Journal of Defense Modeling and Simulation: Applications, Methodology, Technology, 13, 139-151. doi:10.1177/1548512914548615

[Appendix follows] 


\section{Appendix}

\section{Department of Defense and U.S. Military Acronyms}

$\begin{array}{ll}\text { ACAT } & \text { Acquisition category } \\ \text { AHRPO } & \text { Army Human Research Protection Office } \\ \text { ARCIC } & \text { Army Capabilities Integration Center } \\ \text { AROC } & \text { Army Requirements Oversight Council } \\ \text { ARI } & \text { Army Research Institute } \\ \text { CDD } & \text { Capabilities development document } \\ \text { CPD } & \text { Capabilities production document } \\ \text { CoE } & \text { Center of Excellence } \\ \text { CoS } & \text { Chief of staff of the Army } \\ \text { DAS } & \text { Defense Acquisition System } \\ \text { DAU } & \text { Defense Acquisition University } \\ \text { DAWIA } & \text { Defense Acquisition Workforce Improvement Act } \\ \text { DOD } & \text { Department of Defense } \\ \text { DoDI } & \text { Department of Defense Instruction } \\ \text { DOTmLPF } & \text { Doctrine, organization, training, material, logistics, personnel, facilities } \\ \text { GAO } & \text { Government Accountability Office } \\ \text { JCIDS } & \text { Joint Capability Integrated Development System } \\ \text { JROC } & \text { Joint Requirements Oversight Council } \\ \text { JUNS } & \text { Joint user need statement } \\ \text { KPP } & \text { Key performance parameter } \\ \text { MCoE } & \text { Maneuver Center of Excellence } \\ \text { MDAP } & \text { Major Defense Acquisition Program } \\ \text { ONS } & \text { Operational need statement } \\ \text { PPBS } & \text { Planning Programming and Budget System } \\ \text { USD AT\&L } & \text { Under Secretary of Defense for Acquisition Technology and Logistics } \\ \text { USSOCOM } & \text { United States Special Operations Command } \\ & \end{array}$

The International Journal of Applied Management and Technology (IJAMT), sponsored by Walden University's School of Management, is a peer-reviewed, online journal that addresses contemporary national and international issues related to management and technology. The objectives of the IJAMT are to: (a) encourage collaborative and multi-disciplinary examinations of important issues in business and technology management, and (B) engage scholars and scholar-practitioners in a dynamic and important dialogue.

Walden University Publishing: http://www.publishing.waldenu.edu 